\title{
Going to the extremes
}

\section{An intercomparison of model-simulated historical and future changes in extreme events}

\author{
Claudia Tebaldi • Katharine Hayhoe • \\ Julie M. Arblaster • Gerald A. Meehl
}

Published online: 15 March 2007

(C) Springer Science + Business Media B.V. 2007

\section{Erratum to: Climatic Change (2006) 79: 185-211 DOI: $10.1007 / \mathbf{s 1 0 5 8 4 - 0 0 6 - 9 0 5 1 - 4}$}

We discovered an error in the program that plotted the time series of the indices' global average in Figs. 1 and 2. Rather than averaging the indices' values over land points only, for some of the indices the global averages include ocean points as well. None of the temperature indices (left column in Figs. 1 and 2) are affected by the error, nor is the precip intensity index (fourth panel on the right hand side of the figures).

The only indices' trends affected by the correction, that we now show in two figures downloadable from http://www.cgd.ucar.edu/ccr/publications/tebaldi-extremes.html, are the remaining precipitation indices (dry days, precip $>10$, 5-day precip and precip $>95$ th). However, none of the trends affected sees a qualitative change in its direction. Only the range of the y-axis is different in the new version of the figures.

The correction does not change the discussion in the article, which is based on qualitative tendencies and significance of the future trends (unaffected by the revised

The online version of the original article can be found at: doi:10.1007/s10584-006-9051-4.

C. Tebaldi $(\bowtie)$

Institute for the Study of Society and Environment, National Center for Atmospheric Research (NCAR), PO BOX 3000, Boulder, CO 80301, USA

e-mail: tebaldi@ucar.edu

K. Hayhoe

Department of Atmospheric Sciences, University of Illinois at Urbana-Champaign,

Urbana, IL, USA

K. Hayhoe

Department of Geosciences, Texas Tech University, Lubbock, TX, USA

J. M. Arblaster · G. A. Meehl

Climate and Global Dynamics Division, NCAR, Boulder, CO, USA

J. M. Arblaster

Bureau of Meteorology Research Centre, Melbourne, Australia 
computations). The only corrections that need to be considered pertain to a few results in Table 2 (which are not discussed in the body of the article) and which regard the trends in the current climate simulations as they compare to observed trends.

Specifically, for 5 -day precip and precip $>95$ th, now 5 out of 9 models have a significant increasing trend which amounts to a majority (we list only "a minority" having significant trends in the table).

For precip $>10$, now a majority of models (not "all") show an increasing trend, with only two of them being statistically significant.

For dry days, 7 out of 9 models (not "all") show increasing trends, with only one statistically significant.

In all, we consider these changes minor, not affecting in any aspect the development and conclusions of our study.

However we want the interested reader to have access to the corrected figures, using the same link that we already referred to in the paper for access to additional plots not included in the article (e.g., hemispheric averages). 